\title{
Evaluation of Laparoscopic Cholecystectomy in Acute Cholecystitis
}

\author{
Al-Ashry T. Ghoneim ${ }^{\text {a }}$, Hasan El-Soueni ${ }^{\text {a }}$, Mohammed Mahmoud ${ }^{\text {a }}$, Wael A. El-Dawy ${ }^{\text {b }}$
}

Department of General
Surgery, Benha faculty of
medicine, Benha University,
Egypt. b Department General
Surgery, Damanhur teaching
Hospital, Egypt
Correspondence to: Wael A.
El-Dawy, Department General
Surgery, Damanhur teaching
Hospital, Egypt
Email:

Received: 11 November 2019

Accepted: 2 December 2019

\begin{abstract}
Background: Acute cholecystitis (AC) is defined as acute inflammation involving the gallbladder wall. This study was analytical prospective study, included 50 patients, who presented with acute calculus cholecystitis. All the patients were treated by early laparoscopic cholecystectomy (LC). Methods: The diagnosis AC was made clinically followed by ultrasonography in all patients according to revised Tokyo guidelines diagnostic and severity assessment criteria 2013. According to the severity, the patients were divided in into mild $(n=26))$ and moderate groups $(n=24))$, while according to timing of surgery, the patients were divided into group 1: $\leq 3$ days from the onset of symptoms $(n=26)$, group $2:>3$ days to $\leq 7$ days $(n=16)$ and group 3: $>7$ days $(n=8)$. Results: the mean of intraoperative blood loss was significantly larger in the moderate group. A delay in the timing of surgery was associated with higher incidence of intraoperative difficulties. Moderate group
\end{abstract} and delayed surgery was associated with higher incidence of postoperative complications and a significant longer operative time and being associated with larger amounts of intraoperative blood loss. Conclusion: LC for both grade I and grade II AC according Tokyo guidelines 2013 severity assessment is safe and feasible procedure and should be performed as early as possible, as early LC is associated with the least complications and least intraoperative difficulty particularly when performed within seven days from the onset of symptoms.

Key Words: Acute cholecystitis, cholecystectomy, Tokyo Guidelines 



\section{Introduction}

Gallstones are present in about $10 \%$ to $15 \%$ of the adult western population. Between $1 \%$ and $4 \%$ of these adults become symptomatic in a year (the majority due to biliary colic but a significant proportion due to acute cholecystitis). Acute cholecystitis is secondary to gallstones in $90-95 \%$ of cases. ${ }^{1}$ Mostly, an impacted gallstone in the gallbladder infundibulum or in the cystic duct is the cause for the inflammatory process. The continuing mucin production from the gallbladder's epithelium in combination with the impacted gallstone results in gallbladder distension and edema with acute inflammation. This can eventually result in micro- and macrocirculatory perfusion deficits with subsequent ischemia, necrosis and may be complicated by secondary infection which occurs in the majority of patients with acute cholecystitis. ${ }^{2}$

The diagnosis of $\mathrm{AC}$ is based on a combination of clinical criteria (acute right upper quadrant tenderness, temperature exceeding $37.5^{\circ} \mathrm{C}$, and white blood cell count greater than $10 \times 10 \%$ 1) and Ultrasonographic criteria (thickened, edematous, distended gallbladder; positive sonographic Murphy's sign; presence of gallstones; and pericholecystic fluid collection). ${ }^{3}$
Laparoscopic cholecystectomy in acute cholecystitis is mainly performed after the acute cholecystitis episode settles because of the fear of higher morbidity and of need for conversion from laparoscopic to open cholecystectomy. The conventional approach for management of acute calculus cholecystitis has traditionally been the initial control of inflammation and an interval cholecystectomy 4-6 weeks later. ${ }^{4}$

Early in the laparoscopic era, acute cholecystitis was considered to be a relative contra-indication for laparoscopic cholecystectomy. This was challenged by studies advocating early surgery for acute cholecystitis. Early laparoscopic cholecystectomy, within 72 hours of presentation, has been advocated because of shorter hospital stay, decreased financial costs and reduced readmission rates. ${ }^{5}$

Many general surgeons still prefer to manage acute cholecystitis non-operatively initially and perform a delayed laparoscopic cholecystectomy. Previously cited reasons against early laparoscopic cholecystectomy include the increased technical difficulties, increased risk of conversion to an open procedure (6-35\% in some studies) and increased risks of biliary complications such as bile leaks and common bile duct injuries when operating on an inflamed gallbladder 
with oedematous planes and distorted anatomy. ${ }^{6}$ Several studies showed that early laparoscopic cholecystectomy is comparable to delayed laparoscopic cholecystectomy in terms of conversion rate, postoperative morbidity. Despite this evidence, a delayed laparoscopic cholecystectomy performed at least six-eight week after the symptoms onset is still frequently preferred to early laparoscopic cholecystectomy in clinical practice. $^{6}$

There is still a considerable debate over the timing of laparoscopic cholecystectomy in acute cholecystitis. In the pre-laparoscopic era, prospective randomized studies demonstrated that early cholecystectomy within 7 days of the onset of symptoms was the preferred strategy to manage the acutely inflamed gallbladder, because of shorter hospital stay and reduced potential risk of late complications such as gangrenous or emphysematous cholecystitis, without an increase of postoperative morbidity and mortality. 5

Initial conservative management with antibiotics, followed by interval elective cholecystectomy, was associated with reduced complications and conversion rates. However, recently this concept has been challenged and same-admission laparoscopic cholecystectomy for acute cholecystitis is associated with better outcomes. Early laparoscopic cholecystectomy is currently the recommended treatment for acute cholecystitis. Furthermore, delaying cholecystectomy during the same admission increases hospital stay without any outcome benefits. $^{7}$

\section{$\overline{\operatorname{Aim}}$}

To evaluate the safety and feasibility of laparoscopic cholecystectomy in patients with acute cholecystitis.

\section{Patients and Methods}

This study was analytical prospective study, which includes a total of 50 patients who present with acute calculus cholecystitis admitted in the general surgery department at Damanhur Medical National Institute in the period from April 2016 to December 2018. The diagnosis of acute calculus cholecystitis will be made clinically (history taking, general and local examination) and followed by ultrasonography in all patients.

Included patients were those who meet the diagnostic criteria of acute cholecystitis, as a definite diagnosis, according to revised Tokyo guidelines (TG13/TG18), those with grade I (mild) and grade II (moderate) acute cholecystitis according to TG13/TG18 severity assessment criteria, Those who are 
ASA-PS $<$ III, CCI $<6$. In all patients, gallstone disease will be confirmed by ultrasonographic detailed examination.

In order to assess the best timing for $\mathrm{LC}$, the patients were divided into 3 groups;

Group 1: surgery was performed within 3 days or less from the onset of symptoms.

Group 2: surgery was performed from $>3$ days to $\leq 7$ days from the onset of symptoms.

Group 3: surgery was performed more than 7 days from the onset of symptoms.

All the patients were treated by early after admission (same day or on next day morning) laparoscopic cholecystectomy. laparoscopic cholecystectomy was done to all patients

The observations to be noted:

1. Time of presentation / Timing of surgery.

2. Severity of acute cholecystitis: mild or moderate according TG13/18 (severe cases are excluded from study)

3. Operative findings

4. Operative time: from first port insertion to last port site closure.
5. Conversion to open cholecystectomy.

6. Morbidity

7. Total hospital stay - defined as time spent in hospital for all hospital admissions

8. Mortality rate.

\section{Statistical analysis}

Data were fed to the computer and analyzed using IBM SPSS software package version 20.0. (Armonk, NY: IBM Corp). ${ }^{8}$ Qualitative data were described using number and percent. The Kolmogorov-Smirnov test was used to verify the normality of distribution Quantitative data were described using range (minimum and maximum), mean, standard deviation and median. Significance of the obtained results was judged at the $5 \%$ level.

\section{Results}

Fifty two of the patients were presented with mild attack of acute cholecystitis $(n=26)$ according to severity assessment criteria of TG13, while $48 \%$ of patients were presented with moderate attack of $A C(n=24)$.

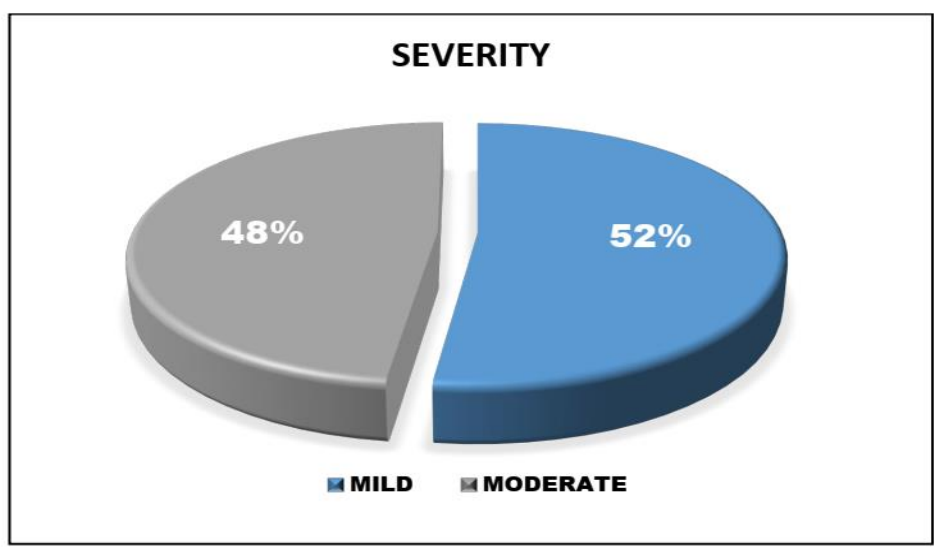


Figure 1: Distribution of studied cases according to Severity.

The patient were divided into three groups according to the time of surgery (Timing Groups)

Group 1: Surgery was performed three days or less from the onset of symptoms. This group included 26 patients.

Group 2: Surgery was performed more than 3 days to 7 days from the onset of symptoms. This group included 16 patients.

Group 3: Surgery was performed after 7 days from the onset of symptoms. This group included 8 patients.

Table 1: Statistical and comparative analysis between mild and moderate group according to intraoperative findings.

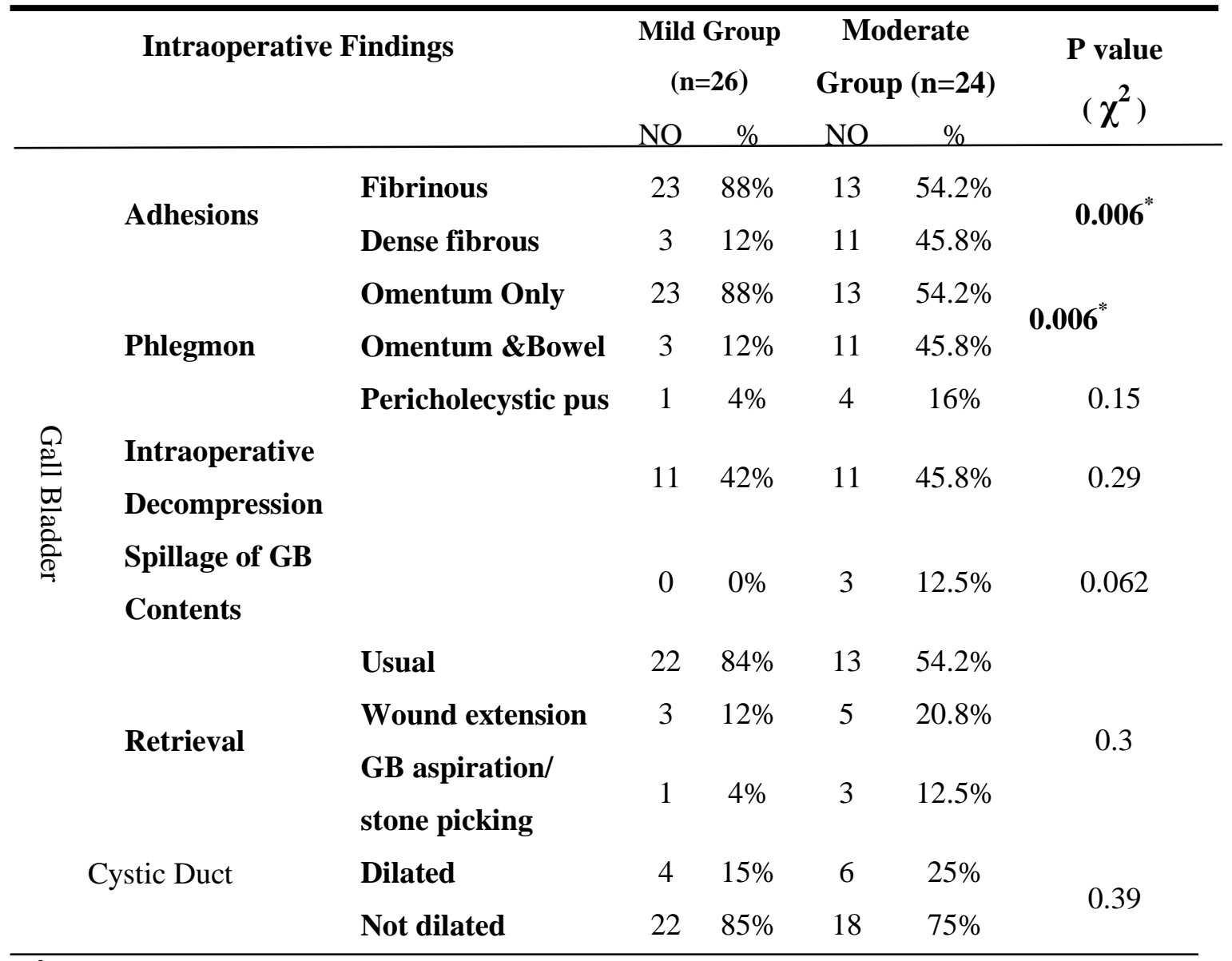

$\chi^{2}$; chi-square test, $\mathrm{p}$; probability value, $*$; statistically significant $(\mathrm{p}<0.05)$. 
Benha medical journal vol. 37, special issue (surgery), 2020

Table 2: Statistical and comparative analysis between mild and moderate group according to intraoperative blood loss and operative time and their significance.

\begin{tabular}{clccc}
\hline & Mild group & $\begin{array}{c}\text { Moderate group } \\
(\mathbf{n = 2 6})\end{array}$ & $\begin{array}{c}\text { P value } \\
(\text { F-test) }\end{array}$ \\
\hline \multirow{4}{*}{ Operative time } & Mean & 47.12 & 72.54 & \\
& Min - Max & $35-70$ & $45-120$ & $<\mathbf{0 . 0 0 1}^{*}$ \\
& Median & 45.5 & 65 & \\
& STD & 8.85 & 21.93 & \\
& Mean & 28.08 & 84.17 & \\
Blood loss & Min - Max & $10-100$ & $20-225$ & $<\mathbf{0 . 0 0 1}^{*}$ \\
& Median & 22.5 & 60 & \\
\hline & STD & 21.68 & 60.1 & \\
\hline
\end{tabular}

F; Exact Fisher test, *; statistically significant $(\mathrm{p}<0.05)$

Table 3: Statistical and comparative analysis between mild and moderate group according to postoperative complications and conversion to open and their significance

\begin{tabular}{|c|c|c|c|c|c|c|}
\hline \multirow{2}{*}{\multicolumn{2}{|c|}{ Postoperative complications: }} & \multicolumn{2}{|c|}{$\begin{array}{l}\text { Mild group } \\
\quad(n=26)\end{array}$} & \multicolumn{2}{|c|}{$\begin{array}{l}\text { Moderate group } \\
\quad(n=24)\end{array}$} & \multirow{2}{*}{$\begin{array}{c}\text { P value } \\
\left(\chi^{2}\right)\end{array}$} \\
\hline & & No & $\%$ & NO & $\%$ & \\
\hline & $\begin{array}{l}\text { leak or bile } \\
\text { uct injury }\end{array}$ & 0 & $0 \%$ & 0 & $0 \%$ & 0.47 \\
\hline & Seroma & 0 & $0 \%$ & 1 & $4 \%$ & 0.29 \\
\hline Por & site infection & 0 & $0 \%$ & 1 & $4 \%$ & 0.29 \\
\hline & Fever & 2 & $7.7 \%$ & 9 & $37.5 \%$ & $0.011^{*}$ \\
\hline & Bleeding & 0 & $0 \%$ & 0 & $0 \%$ & 0.47 \\
\hline & Ileus & 0 & $0 \%$ & 1 & $4 \%$ & 0.29 \\
\hline \multirow{3}{*}{ Pain } & Mild & 21 & $81 \%$ & 12 & $50 \%$ & \multirow{3}{*}{$0.038^{*}$} \\
\hline & Moderate & 5 & $19 \%$ & 9 & $37.5 \%$ & \\
\hline & Severe & 0 & $0 \%$ & 3 & $12.5 \%$ & \\
\hline \multirow{4}{*}{$\begin{array}{l}\text { Analgesia } \\
\text { Dose/day }\end{array}$} & Ketorolac $30 \mathrm{mg}$ & 21 & $81 \%$ & 12 & $50 \%$ & \multirow{4}{*}{$0.038^{*}$} \\
\hline & Ketorolac $60 \mathrm{mg}$ & 5 & $19 \%$ & 9 & $37.5 \%$ & \\
\hline & Ketorolac $90 \mathrm{mg}$ & 0 & $0 \%$ & 3 & $12.5 \%$ & \\
\hline & Nalbuphine $20 \mathrm{mg}$ & 0 & $0 \%$ & 3 & $12.5 \%$ & \\
\hline $\begin{array}{c}\text { Open } \\
\text { Conversion }\end{array}$ & & 0 & $0 \%$ & 3 & $12.5 \%$ & 0.062 \\
\hline
\end{tabular}

$\chi^{2}$; chi-square test, ${ }^{*}$; statistically significant $(p<0.05)$. 
Table 4: Statistical and comparative analysis between mild and moderate group according to intraoperative blood loss and operative time and their significance.

\begin{tabular}{clccc}
\hline & & $\begin{array}{c}\text { Mild group } \\
(\mathbf{n = 2 6})\end{array}$ & $\begin{array}{c}\text { Moderate group } \\
(\mathbf{n = 2 4})\end{array}$ & P value \\
\hline Mean & 37.05 & 37.49 & \\
$\begin{array}{c}\text { Postoperative } \\
\text { Temperature } \\
\left({ }^{\circ} \mathbf{C}\right)\end{array}$ & Min - Max & $37-37.7$ & $37-39$ & $\mathbf{0 . 0 0 3}^{*}$ \\
& Median & 37 & 37 & $($ F-test $)$ \\
& STD & 0.18 & 0.71 & \\
Analgesic Dose & Mean & 35.77 & 48.75 & \\
$($ Min - Max & $30-60$ & $30-90$ & $\mathbf{0 . 0 3}^{*}$ \\
& Median & 30 & 45 & $(\mathrm{t}$-test $)$ \\
& STD & 12.06 & 21.33 & \\
Hospital Stay & Mean & & 33 & $\mathbf{0 . 0 1 6}^{*}$ \\
$($ hours $)$ & Min - Max & 24 & $24-96$ & $(\mathrm{t}$-test $)$ \\
& Median & & 24 & \\
\hline
\end{tabular}

F; Exact Fisher test, *; statistically significant $(\mathrm{p}<0.05)$

Table 5: Statistical analysis in comparison between the timing groups according intraoperative findings.

\begin{tabular}{|c|c|c|c|c|c|c|c|c|c|}
\hline & \multicolumn{2}{|c|}{ Intraoperative Findings } & \multicolumn{2}{|c|}{$\begin{array}{c}\text { Group } 1 \\
(n=26)\end{array}$} & \multicolumn{2}{|c|}{$\begin{array}{c}\text { Group } 2 \\
(n=16)\end{array}$} & \multicolumn{2}{|c|}{$\begin{array}{c}\text { Group } 3 \\
(\mathbf{n}=8)\end{array}$} & \multirow{2}{*}{$\begin{array}{c}\text { P value } \\
\left(\chi^{2}\right)\end{array}$} \\
\hline & & & NO & $\%$ & $\mathrm{NO}$ & $\%$ & NO & $\%$ & \\
\hline \multirow{7}{*}{ 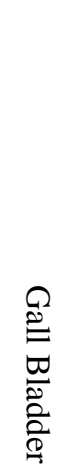 } & \multirow{2}{*}{ Adhesions } & Fibrinous & 23 & $88 \%$ & 11 & $68.75 \%$ & 2 & $25 \%$ & \multirow{2}{*}{$0.002^{*}$} \\
\hline & & Dense fibrous & 3 & $12 \%$ & 5 & $31.25 \%$ & 6 & $75 \%$ & \\
\hline & \multirow{3}{*}{ Phlegmon } & Omentum Only & 23 & $88 \%$ & 11 & $68.75 \%$ & 2 & $25 \%$ & \multirow{2}{*}{$0.002^{*}$} \\
\hline & & Omentum \&Bowel & 3 & $12 \%$ & 5 & $31.25 \%$ & 6 & $75 \%$ & \\
\hline & & $\begin{array}{l}\text { Pericholecystic } \\
\text { pus }\end{array}$ & 1 & $4 \%$ & 1 & $6.25 \%$ & 3 & $37.5 \%$ & $0.034^{*}$ \\
\hline & \multirow{2}{*}{$\begin{array}{l}\text { Intraoperative } \\
\text { Decompression } \\
\text { Spillage of GB } \\
\text { Contents }\end{array}$} & & 11 & $42 \%$ & 8 & $50 \%$ & 3 & $37.5 \%$ & 0.89 \\
\hline & & & 0 & $0 \%$ & 1 & $6.25 \%$ & 2 & $25 \%$ & $0.034^{*}$ \\
\hline & \multirow{3}{*}{ Retrieval } & Usual & 22 & $84 \%$ & 11 & $68.75 \%$ & 2 & $25 \%$ & \multirow{3}{*}{$\begin{array}{c}\mathbf{0 . 0 0 7}^{*} \\
(\mathrm{~F})\end{array}$} \\
\hline & & Wound extension & 3 & $12 \%$ & 2 & $12.5 \%$ & 3 & $37.5 \%$ & \\
\hline & & $\begin{array}{l}\text { GB aspiration/ stone } \\
\text { picking }\end{array}$ & 1 & $4 \%$ & 2 & $12.5 \%$ & 1 & $12.5 \%$ & \\
\hline & \multirow{2}{*}{ Cystic Duct } & Dilated & 4 & $15 \%$ & 3 & $19 \%$ & 3 & $37.5 \%$ & \multirow{2}{*}{0.38} \\
\hline & & Not dilated & 22 & $85 \%$ & 13 & $81 \%$ & 5 & $62.5 \%$ & \\
\hline
\end{tabular}

$\chi^{2}$; chi-square test, $p$; probability value, F; Exact Fisher test, *; statistically significant $(p<0.05)$. 
Benha medical journal vol. 37, special issue (surgery), 2020

Table 6: Statistical and comparative analysis operative time and intraoperative blood loss among the timing groups patients and their significance.

\begin{tabular}{llcccc}
\hline & & $\begin{array}{c}\text { Group 1 } \\
(\mathbf{n = 2 6})\end{array}$ & $\begin{array}{c}\text { Group 2 } \\
(\mathbf{n = 2 4})\end{array}$ & $\begin{array}{c}\text { Group 3 } \\
(\mathbf{n = 8})\end{array}$ & P value \\
\hline Mean & 47.12 & 62.19 & 93.25 & \\
Operative time & Min - Max & $35-70$ & $45-105$ & $68-120$ & $\mathbf{0 . 0 0 1}^{*}$ \\
& Median & 45.5 & 58.5 & 90.5 & $($ t-test $)$ \\
& STD & 8.85 & 15.41 & 18.34 & \\
& Mean & 28.08 & 56.25 & 140 & \\
& Min - Max & $10-100$ & $20-150$ & $70-225$ & (.005* \\
& Median & 22.5 & 50 & 145 & (F-test) \\
& STD & 21.68 & 36.81 & 60.18 & \\
\hline
\end{tabular}

F; Exact Fisher test, t; Student t-test. *; statistically significant $(\mathrm{p}<0.05)$

Table 7: Statistical analysis in comparison between the timing groups according postoperative complications.

\begin{tabular}{|c|c|c|c|c|c|c|c|c|}
\hline \multirow{2}{*}{\multicolumn{2}{|c|}{ Postoperative complications: }} & \multicolumn{2}{|c|}{$\begin{array}{c}\text { Group } 1 \\
(\mathrm{n}=26)\end{array}$} & \multicolumn{2}{|c|}{$\begin{array}{c}\text { Group } 2 \\
(\mathrm{n}=16)\end{array}$} & \multicolumn{2}{|c|}{$\begin{array}{c}\text { Group } 3 \\
(\mathrm{n}=8)\end{array}$} & \multirow{2}{*}{$\begin{array}{c}\text { P value } \\
\left(\chi^{2}\right)\end{array}$} \\
\hline & & NO & $\%$ & NO & $\%$ & NO & $\%$ & \\
\hline \multicolumn{2}{|c|}{$\begin{array}{l}\text { Bile leak or bile } \\
\text { duct injury }\end{array}$} & 0 & $0 \%$ & 0 & $0 \%$ & 0 & $0 \%$ & 0.28 \\
\hline \multicolumn{2}{|c|}{ Seroma } & 0 & $0 \%$ & 0 & $0 \%$ & 1 & $12.5 \%$ & 0.17 \\
\hline \multicolumn{2}{|c|}{ Port site infection } & 0 & $0 \%$ & 0 & $0 \%$ & 1 & $12.5 \%$ & 0.17 \\
\hline \multicolumn{2}{|l|}{ Fever } & 2 & $8 \%$ & 3 & $19 \%$ & 6 & $75 \%$ & $<0.001 *$ \\
\hline \multicolumn{2}{|l|}{ Bleeding } & 0 & $0 \%$ & 0 & $0 \%$ & 0 & $0 \%$ & 0.28 \\
\hline \multicolumn{2}{|l|}{ Ileus } & 0 & $0 \%$ & 0 & $0 \%$ & 1 & $12.5 \%$ & 0.17 \\
\hline \multirow{3}{*}{ Pain } & Mild & 21 & $81 \%$ & 9 & $56.25 \%$ & 3 & $37.5 \%$ & \multirow{3}{*}{$0.041 *$} \\
\hline & Moderate & 5 & $19 \%$ & 6 & $37.5 \%$ & 3 & $37.5 \%$ & \\
\hline & Severe & 0 & $0 \%$ & 1 & $6.25 \%$ & 2 & $25 \%$ & \\
\hline \multirow{4}{*}{$\begin{array}{l}\text { Analgesia } \\
\text { Dose/day }\end{array}$} & Ketorolac $30 \mathrm{mg}$ & 21 & $81 \%$ & 9 & $56.25 \%$ & 3 & $37.5 \%$ & \multirow{4}{*}{$0.041^{*}$} \\
\hline & Ketorolac $60 \mathrm{mg}$ & 5 & $19 \%$ & 6 & $37.5 \%$ & 3 & $37.5 \%$ & \\
\hline & Ketorolac $90 \mathrm{mg}$ & 0 & $0 \%$ & 1 & $6.25 \%$ & 2 & $25 \%$ & \\
\hline & $\begin{array}{l}\text { Nalbuphine } 20 \\
\text { mg }\end{array}$ & 0 & $0 \%$ & 1 & $6.25 \%$ & 2 & $25 \%$ & \\
\hline \multicolumn{2}{|l|}{$\begin{array}{l}\text { Open } \\
\text { Conversion }\end{array}$} & 0 & $0 \%$ & 1 & $6.25 \%$ & 2 & $25 \%$ & $0.034 *$ \\
\hline
\end{tabular}

$\chi^{2}$; chi-square test, ${ }^{*}$; statistically significant $(p<0.05)$. 
Table 8: Statistical and comparative analysis postoperative temperature, analgesic dose and hospital stay in the timing groups and their significance.

\begin{tabular}{|c|c|c|c|c|c|}
\hline & & $\begin{array}{c}\text { Group } 1 \\
(n=26)\end{array}$ & $\begin{array}{c}\text { Group } 2 \\
(n=24)\end{array}$ & $\begin{array}{c}\text { Group } 3 \\
(\mathbf{n}=8)\end{array}$ & $P$ value \\
\hline \multirow{3}{*}{$\begin{array}{c}\text { Postoperative } \\
\text { Temperature } \\
\left({ }^{\circ} \mathbf{C}\right)\end{array}$} & Mean & 37.05 & 37.3 & 37.9 & \multirow{4}{*}{$\begin{array}{l}\mathbf{0 . 0 1 6} \\
\text { (t-test) }\end{array}$} \\
\hline & Min - Max & $37-37.7$ & $37-39$ & $37-39$ & \\
\hline & Median & 37 & 37 & 37.75 & \\
\hline \multirow{4}{*}{$\begin{array}{l}\text { Analgesic } \\
\text { (dose/day) }\end{array}$} & STD & 0.18 & 0.54 & 0.8 & \\
\hline & Mean & 35.77 & 45 & 56.25 & \multirow{4}{*}{$\begin{array}{l}\mathbf{0 . 0 0 3}^{*} \\
\text { (F-test) }\end{array}$} \\
\hline & Min - Max & $30-60$ & $30-90$ & $30-90$ & \\
\hline & Median & 30 & 30 & 60 & \\
\hline \multirow{5}{*}{$\begin{array}{l}\text { Hospital stay } \\
\text { (hours) }\end{array}$} & STD & 12.06 & 18.97 & 25.04 & \\
\hline & Mean & & 27 & 45 & \multirow{4}{*}{$\begin{array}{l}<\mathbf{0 . 0 0 1 *} \\
\text { (F-test) }\end{array}$} \\
\hline & Min - Max & 24 & $24-48$ & $24-96$ & \\
\hline & Median & & 24 & 48 & \\
\hline & STD & 0 & 8.2 & 23.9 & \\
\hline
\end{tabular}

F; Exact Fisher test, t; Student t-test. *; statistically significant $(\mathrm{p}<0.05)$.

\section{Discussion}

The present study included fifty patients with mild and moderate acute calculus cholecystitis, to all of them early LC was performed, aiming at evaluating the feasibility and safety of LC by assessing the impact of severity of disease on the intraoperative difficulty and the rate of postoperative complication in cases with AC. As there is a controversy over the timing of laparoscopic cholecystectomy in $\mathrm{AC}$, this study aimed also at recognizing which time is best for surgery. The mean time of surgery days was (4.18 \pm 2.59 days) and the range was (1-11 days). In the mild group, LC was

performed within three days from the onset of symptoms. The mean time in days was (2.27 \pm 0.8$)$ and the range was (1-3). All patients of the moderate group were presented more after three days from the onset of symptoms and the mean time of surgery in days was $(6.25 \pm 2.25)$ and the range was (4-11 days). The difference between mild and moderate groups is statistically significant $(\mathrm{p}<0.001)$. The 
findings agreed another study done on 2014 where it was reported that the mean time of surgery in mild group $(2 \pm 0.9)$ with range (13) days. ${ }^{9}$ The mean time was also longer in the moderate $(5.84 \pm 2.62)$ with range (4-15) days. In a different study done somewhat later on 2017 it was also reported that the mean time in the mild group $(1.8 \pm 0.7)$ with range (1-3) days, which was longer in the moderate group with mean $(6.6 \pm 3.1)$ with range (4-10) days. ${ }^{10}$

As regards intraoperative findings, the most determinants of intraoperative difficulties is the presence and the type of adhesions forming the gall bladder phlegmons. ${ }^{11}$

In our study, the most consistent intraoperative finding was the presence of pericholecystic adhesions and gall bladder phlegmons which were present in all patients. Fibrinous adhesions were found in $72 \%$ of cases, while dense adhesions were found in $28 \%$ of cases.

This was in agreement with the results of the study done on 2013, which reported the presence of pericholecystic adhesions and gall bladder phlegmons in all patients included in their study. ${ }^{12}$ Again, in another study done on 2013, the same results were also reported. ${ }^{13}$ However, similar results were reported in pericholecystic adhesions and phlegmons to be in $94 \%$ of patients. ${ }^{14}$
Eighty eight percent of the adhesions were fibrinous in the mild group versus $54 \%$ of the moderate group, however the dense adhesions were found in only $12 \%$ of the mild group versus $46 \%$ of the moderate group. The difference between both groups being statistically significant $(\mathrm{p}=0.006)$.

This was correlated with a study done on 2017, which reported a higher incidence of dense adhesions in the moderate group than mild group (52\% versus $10 \%$ respectively) however, the incidence of fibrinous adhesions was higher in the mild group than moderate group $(90 \%$ versus $48 \%$ respectively). ${ }^{10}$

This also was correlated with the results of the study done on 2014 by researchers, who reported higher incidence of dense adhesions in the moderate group than the mild group (59\% versus $16 \%$ respectively) and higher incidence of fibrinous adhesions in the mild group than moderate group ( $84 \%$ versus $41 \%$ respectively). ${ }^{9}$

There was a higher incidence of dense adhesions (75\%) in "the delayed" group 3 than the intermediate group 2 (31.25\%) than the early group $1(12 \%)$. However, adhesions seen in of the early group were mainly fibrinous $(88 \%)$, seen in $68.75 \%$ of patients in group 2 (4-7 days) and 25\% of the delayed 
group 3. The difference among these groups being statistically significant $(\mathrm{p}=0.002)$.

The results of the present study are in line with the study done before hand in 2015 in which it was reported that adhesions were seen in 19 cases out of twenty five, which were either flimsy or friable, and that 17 patients had dense adhesions in the interval group. 6

This can be explained by the fact that in the early phase of acute inflammation, adhesions are easily separated and there is usually an edematous plane around the gallbladder that facilitates dissection. As time passes, the inflammation and edema are gradually replaced by fibrotic adhesions between the gall bladder and surrounding structures. ${ }^{6}$

The constituents of gall bladder phlegmons, which may be omentum only, omentum and bowel and/or localized pericholecystic pus collection, were seen in all patients in the present study.

There was a higher incidence of the category (omentum only) in the mild group (88\%), while, seen in $54 \%$ of the moderate group. There was also a higher incidence of the category (omentum and bowel) in the moderate group $46 \%$ versus $12 \%$ in the mild group. This difference between both group being statistically significant $(\mathrm{p}=0.006)$. The incidence of pericholecystic pus collection was higher in the moderate group $16 \%$ versus
$4 \%$ in the mild group and the difference being statistically insignificant $(\mathrm{p}=0.15)$.

The previous results correlated with that the results of the study done on 2017 where it was reported that, higher incidence of gall bladder phlegmon in moderate group (52\%) than mild group (10\%). They also reported a higher incidence of pus collection around the gall bladder in the moderate group $20 \%$ than the mild group (2\%). ${ }^{10}$

This does not correlate with study done on, 2005, where the researchers reported phlegmons in only $25 \%$ of the studied cases, of which, $68 \%$ were omentum only, $25 \%$ omentum and bowel and $7 \%$ were pericholecystic pus. ${ }^{14}$

In the present study, there was a higher incidence of the category omentum only in the early group 1 (88\%) than group 2 $(68.75 \%)$ and least in the delayed group 3 (25\%). However, the category omentum and bowel showed a higher incidence in the delayed group $3(75 \%)$, less in group 2 $(31.25 \%)$ with the least incidence in group 1 (12\%) and this difference being statistically significant $(\mathrm{p}=0.002)$. The incidence of pericholecystic pus collection was also higher in group $3(37.5 \%)$, less in group $2(6.25 \%)$ with the least in group $1(4 \%)$ and this difference also being statistically significant $(\mathrm{p}=0.034)$ 
This was in agreement with results of a previous study which reported higher incidence of omentum and bowel phlegmons in the delayed group $63 \%$ versus $37 \%$ in the early group. ${ }^{12}$ Similar results were also obtained before that phlegmons tend to be complex (omentum and bowel) with the longer time from the onset of symptoms and being simple (omentum only) with the shorter time from the onset of symptoms. ${ }^{13}$

These results are in line with the study done on 2015 where it was reported that phlegmons are seen in $76 \%$ of early group, which of omentum variety, whereas omentum and bowel variety seen in $68 \%$ of the delayed group. ${ }^{6}$ Similar results were reported by studies done on 2016 and 2017, as delayed groups were associated with higher incidences of omentum and bowel phlegmons (67\% and $72 \%$ respectively), however early group were associated with higher incidences of omentum phlegmons (92\% and $83 \%$ respectively). ${ }^{15,16}$

Another common intraoperative finding encountered during LC for AC is the tensely distended and edematous gall bladder, which is difficult to handle. Therefore, needle decompression of an edematous gall bladder was required in $44 \%$ of the studied cases, of which $46 \%$ of patients in the moderate group which was slightly higher than the mild group (42\%). However, the difference is being statistically insignificant. The difference among the timing groups also being statistically insignificant, in which decompression was required in $42 \%$ of group $1,50 \%$ of group 2 and $37.5 \%$ of group 3 . This was correlated with a study on 2013, which reported intraoperative decompression of gall bladder in half of the studied cases. ${ }^{12}$ and also reported decompression $42 \%$ and $39 \%$ of the studied cases respectively. ${ }^{13,17}$ This was in agreement with the study done before hand (2017) which reported a higher incidence of intraoperative decompression in the moderate group than the mild group (55\% versus 50\%). ${ }^{10}$ Similarly, in 2014 it was reported that there was slightly higher incidence of intraoperative decompression in the moderate group than the mild group (37.5\% versus $36 \%$ respectively). ${ }^{9}$

These results is in line with results of several studied; 2014, 2015, 2016 and 2017), all of them reported a higher incidence of decompression in the early group (whether < 72 hours or $<7$ days) than the delayed group. ${ }^{18,6,15,16}$

Spillage of gall bladder contents either bile or stones, occurred only in the moderate group $(12.5 \%)$ and did not occur in any patient of the mild group (statistically insignificant). There was also a higher incidence of dilated 
cystic duct in the moderate group (25\%) than the mild group (15\%) and the difference being statistically insignificant.

There was a higher incidence of spillage of the contents in the delayed group $3(25 \%)$ than group $2(6.25 \%)$ and did not show in the early group 1 (being statistically significant). The incidence of dilated cystic duct was higher in group $3(37.5 \%)$ than group 2 and group 1 (19\% and $15 \%$ respectively) with statistically insignificant difference.

This was correlated with the study which reported the of spillage of contents had been observed in one third of the cases of the moderate group and only in $3 \%$ of the mild group. ${ }^{10,}$ also with the study which reported wide cystic duct in one case of early (group $3 \%$ ). In the delayed group, the cystic duct was wide in 3 cases $(12 \%){ }^{6}$

In $\mathrm{AC}$, the gall bladder being thick, edematous and friable making its retrieval is not an easy task especially when endobag is not available. Therefore, technical modifications may be required for safe retrieval. In the present study, the incidence of difficult retrieval is higher in the moderate group than mild (33.3\% versus $16 \%)$. There was also a higher incidence of difficult retrieval in group 3 than group 2 and being least in group $1(50 \%, 25 \%$ and 16\%) respectively and the difference being statistically significant.
This was correlated with the studies done before, on 2013 and 2015, both of them reported difficult retrieval delayed cases of LC than those who been operated early. ${ }^{6,17}$ In 2017, a higher incidence of difficult retrieval in the grade II AC than grade I AC, also was reported. ${ }^{10}$

Furthermore, it was concluded that difficult retrieval may be avoided by the use of endobags. ${ }^{15,16}$

Blood loss can be considered as a surrogate for the difficulty of a given operation. Intraoperative bleeding has been defined differently. ${ }^{19}$

In the current study, the need for blood transfusion, bleeding that require conversion to open surgery and/or a volume of $500 \mathrm{ml}$ or more were the predictive indicators of significant intraoperative blood loss. Accordingly, there was no significant intraoperative blood loss in all patients. The mean blood loss was $(55 \pm 52.31) \mathrm{ml}$ with rang; (10-225) $\mathrm{ml}$ for all studied cases.

This in line with several studies included in meta-analysis study done by (Cao et al, 2016), wherein, blood loss was reported by seven studies. ${ }^{19}$ Four studies reported the number of cases, there were $2.7 \%$ of cases in the early group and $1.4 \%$ of cases in the delayed group with blood loss. ${ }^{20,17}$ The relative risk of blood loss in early versus delayed groups was 1.47 , whilst three studies 
reported the mean volume of estimated blood loss, the average blood loss was $228 \mathrm{ml}$ in the early group and $114 \mathrm{ml}$ in the delayed group $(p=0.006)$. No patient in either group required blood transfusion. ${ }^{21}$ It was reported that the mean loss was $161 \mathrm{~mL}$ in the early group and $172 \mathrm{~mL}$ in the delayed group. ${ }^{7}$

This was in agreement with the study done on, 2014, which reported an average blood loss being more in the grade II than grade I AC. The mean blood loss was $(100 \pm 25.6)$ $\mathrm{ml}$ in grade II AC, while in grade I, the mean was $(35 \pm 16.2) \mathrm{ml}^{9}$

Similarly, reported before, 2017, that the mean volume in moderate AC was $(130 \pm$ 56.5), whilst, it was $(40 \pm 23.3)$ in mild AC. Unlike our study, the difference in both studies being statistically insignificant. ${ }^{10}$

This goes hand in hand with the study done on 2014, by some researchers, who reported an average blood loss in early LC $36 \mathrm{ml}$, while in the delayed LC the average was 165 $\mathrm{ml}^{18}$

Similar results have been obtained from the studies done on 2016 and 2017), both of them reported that delayed LC was associated with higher volumes of intraoperative blood loss than that observed in early LC cases. ${ }^{15,16}$ An average blood loss of $(170 \pm 97.6)$ with range (80-326) $\mathrm{ml}$ in the delayed LC patients was reported, while in patients with the early
LC, the average was $(32 \pm 15.5)$ with range (15-122) $\mathrm{ml}^{15}$ In another study done 2017, the mean blood loos in the early LC patients was $(52 \pm 17.6) \mathrm{ml}$, while in the delayed LC patients, it was $(155 \pm 43.2) \mathrm{ml}^{16}$ On contrary to the present study, both studies reported that the difference between early and delayed LC was insignificant.

The mean operative time, among all cases in our study, was (59.32 \pm 20.74 minutes) with range (35-120 minutes). Moderate AC was associated with longer operative time than mild AC in minutes [(72.54 \pm 21.93$)$ versus $(47.12 \pm 8.85)$ respectively] and the difference was statistically significant.

Furthermore, early LC was associated with the least operative time $(47.12 \pm 8.85)$ and delayed LC (> 7 days) was associated with the longest operative time (93.25 \pm 18.34 ), while in group 2 (4-7 days), it was $(62.19 \pm 15.41) \quad$ with difference being statistically significant.

It was reported that grade II LC has been associated with prolonged operative time, the average was $(84.3 \pm 18.6)$ minutes while, it was $(52 \pm 6.4)$ in grade I AC. ${ }^{9}$

It was also reported that patients undergoing early LC $(<72$ hours) experienced a significantly shorter a period of operation time than patients undergoing delayed LC (beyond 72 hours) $[44.1 \pm 5.32$ versus $66.4 \pm$ 
$3.05 \mathrm{~min}] .{ }^{22}$ Furthermore, it was in agreement with several studies included in a metaanalysis of case control studies, in which the duration of surgery was reported by 60 studies. The mean duration was $89.3 \mathrm{~min}$ in the early group and $95.7 \mathrm{~min}$ in the delayed group. ${ }^{19}$

Another study reported an increased average duration of the operation from 75.9 minutes to 90 minutes in a delayed cholecystectomy. ${ }^{15}$

This was in contrast with a previous study done on 2014, that reported the mean operative time for LC in the early group was $54.8 \pm 19.9$ (range 35- 90) $\mathrm{min}$. In the delayed LC group was $47.8 \pm 25.0$ (range 25 120) $\min ^{18}$

This also was in contrast with several other studies Meta-analysis of randomized controlled trials, 2015, which reported that a significant heterogeneity among included studies and the operating time was significantly longer in the early group than the delayed group. ${ }^{1}$ Similarly it was reported that early LC was associated with increased duration of operation. Although the mean duration of surgery was increased in the early group, it was not statistically significant. ${ }^{7}$

The overall conversion rate in our study was $6 \%$, there was no incidence of conversion among patients with mild $\mathrm{AC}$, while, the rate was $12.5 \%$ in patients with moderate $\mathrm{AC}$ but the difference being statistically insignificant. This agrees with other studies; that reported an overall conversion rate of $10.5 \%$ in patients with $\mathrm{AC}$, which was higher in the moderate AC (16.12\%) than in the mild $(11.11 \%){ }^{13}$

Conversion to open in $12.5 \%$ of cases, was reported. ${ }^{10}$ Significantly more cases were converted in the moderate group (15 cases: $20.3 \%)$ compared to the control group (4 cases: $5.1 \%) .{ }^{10}$

However, a much lower rate of conversion; was reported, the overall rate was $0.9 \%$ and the rate in the mild $\mathrm{AC}$ was $0.7 \%$ compared to the moderate $\mathrm{AC}(1.3 \%) .{ }^{9}$ Zhu et al., 2012, reported there was no conversion to open cholecystectomy in their study. ${ }^{22}$

In the present study there was a significant impact of timing of LC on the conversion rate $(\mathrm{p}=0.034)$. There was an increased rate of conversion (25\%) in delayed LC (group 3) versus nil in the early LC (group 1), while the conversion rate in group 2, was $6.25 \%$.

This correlates with the meta-analysis, in which 70 studies reported conversions from laparoscopic to open procedure. $8.8 \%$ of early LC was converted to open procedure, while $10.9 \%$ were converted to open procedure in the delayed group. In the subgroup analyses, the risk of conversions 
was significantly, reduced in the early groups. ${ }^{19}$

It was in contrast with the report that conversion rate was $34.3 \%$ in early LC group and $20.3 \%$ in the delayed LC group ${ }^{18}$, and that there was no significant difference between the two groups regarding conversion to open cholecystectomy. ${ }^{1}$

In the present study, the overall postoperative complications rate was $6 \%$. There was no incidence of bile leak or bile duct injury or postoperative bleeding and no mortality was documented. One patient of the moderate group experienced port site (epigastric) infection (4\%). Another patient of those converted to open cholecystectomy, experienced wound seroma and postoperative ileus. None of these complications were observed in the mild group.

Grade II AC was associated with significant higher incidence of more severe postoperative pain than grade I and consequently, The mean analgesic dose was significantly higher in patients with moderate AC $(48.75 \pm 21.33 \mathrm{mg} /$ day $)$ than it was in patients with mild AC (35.77 \pm 12.06 $\mathrm{mg}$ /day). Grade II AC being also associated with significant higher incidence of postoperative fever $(37.5 \%)$ than grade I $(8 \%)$.
The results of the present study concur with the study which reported that early cholecystectomy was associated with a lower risk of major bile duct injury, they reported an increased incidence of postoperative complications in the moderate AC than mild $\mathrm{AC}$ [0.53\% versus $0.28 \%$ respectively] with an overall complication rate being $11 \%$. In their study, moderate AC was associated with a significant higher severity of postoperative pain than mild $\mathrm{AC}$ and hence with a significant higher dose of postoperative analgesia. ${ }^{9}$

There was no significant impact of timing of surgery on postoperative complication, Seroma, port site infection and postoperative ileus. None of these complications were observed in group 1 or group 2. Complication rate in delayed LC (group 3) was $25 \%$

However, there was significant impact of timing of surgery on the postoperative fever, pain and analgesic dose, meanwhile, there was a higher incidence of elevated postoperative temperature in the delayed group 3 (>7days) $(37.9 \pm 0.8)$ than intermediate group $2(37.2 \pm 0.54)$ and early group 1(37.05 \pm 0.18$)$.

There was a higher incidence of more severe pain in the delayed group 3 than group 2 and being least in the early group 1 . Consequently, postoperative daily dose of 
analgesia was higher in group $3(56.25 \pm 25.04$ $\mathrm{mg} /$ day) than group $2(45 \pm 18.97 \mathrm{mg} /$ day $)$ and being least in the early group $1(35.77 \pm 12.06$ $\mathrm{mg} /$ day).

An overall complication rate was reported to be $17.5 \%$. The only intraoperative complication that occurred in the delayed LC group was a type $\mathrm{D}$ bile duct injury according to the Strasberg's classification. The complication rate was $16.9 \%$ in the early LC group and $18.7 \%$ in the delayed LC group. There wasn't any statistically significant difference between the two groups in terms of complication rate, wound infection, prolonged ileus, urinary tract infection, pulmonary infection, prolonged fever, and iatrogenic biliary lesion. No mortality and 30 days re-admissions were recorded. ${ }^{18}$ In 2015 , no incidence of bile duct injury, bowel injury or any significant blood loss were recorded for either group. There was no incidence of wound infection, prolonged ileus or persistent abdominal pain. No mortality was documented. ${ }^{6}$

There was a general trend towards occurrence of $50 \%$ reduction in bile duct injuries in the early groups. Bile leaks reported in the early group (1.7\%) and in the delayed group $(2.3 \%)$. There was a similar trend of fewer bile leaks in the early compared with delayed groups. Wound infections rate in the early group was $(2.7 \%)$ and $(4.1 \%)$ in the delayed group. In the subgroup analysis, there was a general trend towards decreased wound infections in the early compared with delayed groups. Mortality was significantly lower in the early compared with delayed groups. Mortality rate was $0.47 \%$ in the early group and $0.78 \%$ in the delayed group.

Finally, the results of the present study were in line with the studies done in 2016 and 2017, both of them reported that delayed LC was associated with significant higher rate of complications compared to early LC. ${ }^{15,16}$ They reported a complication rate in the delayed LC of $23.6 \%$ versus $3 \%$ in the early LC. ${ }^{15,16}$

The mean of the hospital stay, in the present study, was $(28.32 \pm 12.54)$ hours, with range (24-96) hours. The severity of AC has a significant impact on the hospital stay $(\mathrm{p}=0.016)$. The mean was $(33 \pm 17.06)$ hours in moderate group, while, in the mild group, it was 24 hours.

This was in agreement with previous study done before, which reported the length of stay sequentially increased with disease severity, meanwhile, patients with grade I $\mathrm{AC}$ had a significant decreased length of stay compared to patients with grade II AC. The median length of stay was 2 days in grade I AC versus 5 days in grade II. ${ }^{23}$ 
In the current study, the time of surgery has a significant impact on the hospital stay $(\mathrm{p}<$ 0.001). The hospital stay was significantly longer in the delayed group 3 in which the mean was ( $45 \pm 23.9$ hours) than as it was in group2 (27 \pm 8.2 hours) and being least in the early group 1 (24 hours).

This was in agreement with what was reported by the researchers before that the mean total hospital stay was 6.3 (range 3-13) days and 10.5 (range 7-23) days for early LC and delayed LC group, respectively, with a statistically significant difference. ${ }^{18}$

Finally, the results of our study concur with others which reported, the difference in the mean duration of total hospital stay between the early group (3.08 days) and the interval group (6.28) was statistically significant. ${ }^{16}$

\section{References:}

1. Gurusamy K, Samraj K, Gluud C, Wilson E, Davidson BR. (2015) Meta-analysis of randomized controlled trials on the safety and effectiveness of early versus delayed laparoscopic cholecystectomy for acute cholecystitis. $\mathrm{Br} \mathrm{J}$ Surg; 97:141-50.

2. Hartwig Werner, Büchler Markus W.; (2014) Acute Cholecystitis Early Versus Delayed Surgery; Advances in Surgery 48: 155-164.

3. Yokoe M, Takada T, Strasberg SM, et al. (2013) New diagnostic criteria and severity assessment of acute cholecystitis in revised Tokyo guidelines. $\mathbf{J}$ Hepatobiliary Pancreat Sci; 19(5): 578-85.

4. Cheng Y, Leng J, Tan J, Chen K, Dong J (2013) Proper surgical technique approved for early laparoscopic cholecystectomy for non-critically ill elderly patients with acute cholecystitis. Hepatogastroenterology 60(124):688-691.

5. Inoue Koetsu, Ueno Tatsuya, Daisuke Douchi: (2017) Risk factors for difficulty of laparoscopic cholecystectomy in grade II acute cholecystitis according to the Tokyo guidelines 2013; BMC Surgery 17:114.

6. Bansal Anand Rai, Vikas Arora, Amit Dangi, Rajesh Godara; (2015). Evaluation of Early Versus Interval Laparoscopic Cholecystectomy in Acute Calculus Cholecystitis; Hellenic J Surg; 87:3, 224-228.

7. Wu X.-D., X. Tian, M.-M. Liu, L. Wu, S. Zhao and L. Zhao; (2016) Meta-analysis comparing early versus delayed laparoscopic cholecystectomy for acute cholecystitis; BJS; 102: 1302-1313.

8. Kirkpatrick LA, Feeney BC (2013): A simple guide to IBM SPSS statistics for version 20.0. Student ed. Belmont, Calif.: Wadsworth, Cengage Learning.

9. De Mestral C, Rotstein OD, Laupacis A, Hoch JS, Zagorski B, Alali AS, Nathens AB (2014)Comparative operative outcomes for early and delayed cholecystectomy for acute cholecystitis. Ann Surg 259:10-15.

10. Loozen Charlotte S. Maaike M. Blessing Bert van Ramshorst Hjalmar C. van Santvoort Djamila Boerma; (2017) The optimal treatment of patients with mild and moderate acute cholecystitis: time for a revision of the Tokyo Guidelines; Surg Endosc; DOI 10.1007/s00464-016-5412-x.

11. Ambe PC, Weber SA, Wassenberg DI. (2016) Gallbladder inflammation more severe in male patients presenting with acute cholecystitis? BMC Surg.; 15:48.

12. Brooks KR, Scarborough JE, Vaslef SN, Shapiro ML (2013) No need to wait: an analysis of the timing of cholecystectomy during admission for acute cholecystitis using the American College of Surgeons National Surgical Quality Improvement Program database. J Trauma Acute Care Surg 74:167-174.

13. Barcelo M, Cruz-Santamaria DM, Alba-Lopez C (2013). Advantages of early cholecystectomy in clinical practice of a tertiary care center. Hepatobiliary Pancreat Dis Int 12:87-93. 
14. Sinha Rajeev, Sharma Neeta; (2005) Acute Cholecystitis and Laparoscopic Cholecystectomy; JSLS 6:65-68.

15. Rajcok M, Bak V, Danihel L, Kukucka M, Schnorrer M: (2016) Early versus delayed laparoscopic cholecystectomy in treatment of acute cholecystitis. Br Med J. 117(6):328-31.

16. Rehman S, Afzal M, Butt MQ ; (2017). Outcomes of laparoscopic cholecystectomy in acute cholecystitis. Pak Armed Forces Med J. 67(1):58-61.

17. Degrate L, Ciravegna AL, Margherita L, Guaglio M, Garancini M, Maternini M, Giordano L, Romano F, Gianotti L, Uggeri F (2013) Acute

20. Johansson M, Thune A, Lundell L. (2002) A prospective randomized trial comparing early versus delayed laparoscopic cholecystectomy in the treatment of acute cholecystitis. J Gastroenterology; 123:24.

21. Kolla S. B., S. Aggarwal, A. Kumar, R. Kumar, S. Chumber, R. Parshad, V. Seen; (2004) Early vs delayed laparoscopic cholecystectomy for acute Cholecystitis; A prospective randomized trial; Surg Endosc 18: 1323-1327.

22. Zhu B, Zhang Z, Wang Y, Gong K, Lu Y, Zhang $N$ (2012) Comparison of laparoscopic cholecystectomy for acute cholecystitis within and beyond $72 \mathrm{~h}$ of symptom onset during emergency admissions.World J Surg. doi:10.1007/s00268012- 1709-78.

23. Wright G. Paul, Kellen Stilwell, Jared Johnson, Matthew T; (2015) Predicting length of stay and conversion to open cholecystectomy for acute cholecystitis using the 2013 Tokyo Guidelines in a US population; J Hepatobiliary Pancreat Sci 22:795-801 cholecystitis: the golden 72-h period is not a strict limit to perform early cholecystectomy. Results from 316 consecutive patients. Langenbecks Arch Surg 398:1129-1136.

18. Minutolo V., Licciardello A., Arena M., NICOSIA A., B. DI Stefano; (2014) Laparoscopic cholecystectomy in the treatment of acute cholecystitis: comparison of outcomes and costs between early and delayed cholecystectomy; European Review ; 18(Suppl 2): 40-46.

19. Cao AM, Eslick G, Cox MR (2016) Early cholecystectomy is superior to delayed cholecystectomy for acute cholecystitis: a metaanalysis. J Gastrointest Surg 19(5):848-857.

To cite this article : Al-Ashry T. Ghoneim, Hasan El-Soueni, Mohammed Mahmoud, Wael A. El-Dawy. Evaluation of Laparoscopic Cholecystectomy in Acute Cholecystitis. BMFJ 2020; 37 (Surgical issue): 1-19. DOI: 10.21608/bmfj.2020.19368.1159 